\title{
Ser professor: representações sociais de docentes iniciantes de escolas privadas
}

\author{
Laeda Bezerra Machado \\ Universidade Federal de Pernambuco - UFPE, Brasil \\ Camila Afonso Ferreira de Araujo \\ Universidade Federal de Pernambuco - UFPE, Brasil \\ Lucivânia Barbosa Evangelista \\ Universidade Federal de Pernambuco - UFPE, Brasil \\ Apoio e financiamento: $\mathrm{CNPq}$
}

\section{RESUMO}

Este artigo identifica as representações sociais do ser professor construídas por docentes iniciantes de instituições particulares situadas em Recife-PE. O aporte teórico utilizado foi a Teoria das Representações Sociais. Representações sociais são saberes comuns que explicam a realidade e orientam as práticas das pessoas. Trata-se de um estudo de campo que utilizou como instrumento de coleta um questionário, respondido por 20 professoras com até cinco anos de carreira. Os resultados revelam uma representação social do ser professor pautada na possibilidade de formação dos sujeitos. Essas representações sociais são marcadas pelos sentimentos de desvalorização e falta de reconhecimento social da docência. Indicamos a necessidade de se pensar alternativas que melhor subsidiem o trabalho do docente iniciante na profissão.

PALAVRAS-CHAVE: Ser professor. Representações Sociais. Escola privada. Iniciante.

\section{BEING A TEACHER: SOCIAL REPRESENTATIONS OF TEACHERS' PRIVATE SCHOOL}

\begin{abstract}
This article identifies the social representations of being a teacher built by beginners teachers of private institutions located in Recife-PE. The theoretical contribution used was the Theory of Social Representations. Social representations are common knowledge that explain reality and guide people's practices. It is a field study that used as a collection tool a questionnaire, answered by 20 teachers with up to five years of career. The results reveal a social representation of being a teacher based on the possibility of formation the subjects. These social representations are marked by feelings of devaluation and lack of social recognition of teaching. We indicate the need to think about alternatives that best subsidize the work of the beginning teacher in the profession.
\end{abstract}

KEYWORDS: Be a teacher. Social Representations. Private school. Beginner. 


\section{SER PROFESOR: REPRESENTACIONES SOCIALES DE DOCENTES INICIANTES DE ESCUELAS PRIVADAS}

\section{RESUMEN}

Este artículo identifica las representaciones sociales del ser profesor construidas por docentes iniciantes de instituciones particulares situadas en Recife-PE. El aporte teórico utilizado fue la Teoría de las Representaciones Sociales. Las representaciones sociales son saberes comunes que explican la realidad y orientan las prácticas de las personas. Se trata de un estudio de campo que utilizó como instrumento de recolección un cuestionario, respondido por 20 profesoras con hasta cinco años de carrera. Los resultados revelan una representación social del ser profesor pautada en la posibilidad de formación de los sujetos. Estas representaciones sociales están marcadas por los sentimientos de devaluación y falta de reconocimiento social de la docencia. Indicamos la necesidad de pensar alternativas que mejor subsidien el trabajo del docente principiante en la profesión.

PALABRAS CLAVE: Ser profesor. Representaciones Sociales. Escuela privada. Principiante.

\section{INTRODUÇÃO}

O foco deste artigo recai sobre docentes iniciantes que atuam em escolas particulares. Investigamos as representações sociais do ser professor construídas por professoras em início de carreira nas instituições privadas do município do Recife-PE.

A literatura sobre o professor iniciante no Brasil tem crescido. Como mostram Lima (2006), Papi e Martins (2009), Corrêa e Portella (2012), Papi e Carvalho (2013) Cunha et al (2013), Machado (2017) essa literatura tem focado os professores iniciantes dos anos iniciais do Ensino Fundamental e do Ensino Superior público. Consideramos a produção científica sobre o tema e admitimos ser relevante um estudo que envolva professores iniciantes que atuem em outros contextos, ou seja, nas instituições privadas. Inferimos que, investigações sobre esses professores e como eles representam a profissão podem dar indicativos a respeito do choque de realidade, isto é, se o estranhamento entre o ideal e a realidade da profissão também ocorre com professores que atuam em contextos diferenciados, menos afetos às dificuldades comuns enfrentadas pelos professores.

Como afirma Lima (2006), o início da docência é uma fase importante e difícil; tem características próprias e influencia a identidade e estilo que vão caracterizar o profissional/professor ao longo de toda a sua carreira. Na visão de Garcia (1999), a fase inicial da carreira é marcada pelo choque de realidade, isto é, a confrontação do professor novato com a complexidade do exercício profissional.

Neste artigo, procuramos identificar as representações sociais de professores iniciantes vinculados a instituições privadas sobre o ser professor, explorando os principais desafios que enfrentam no interior desse tipo de escola e as expectativas desses profissionais diante da 
docência. Tomamos como referência a Teoria das Representações Sociais (TRS) inaugurada, em 1961, pelo psicólogo Serge Moscovici. Este constitui um campo de estudos que valoriza o conhecimento do senso comum.

As representações são elaboradas por meio das interações dos sujeitos em suas práticas sociais. "Elas têm a capacidade de criar uma realidade denominando, objetivando noções e imagens, dirigindo as práticas materiais e simbólicas para esta realidade que lhes corresponde" (MOSCOVICI, 2003, p.96). Representar não é reproduzir aquilo que é comum a um grupo; ao contrário, quando em contato com as formas de comunicação, o sujeito age, recria e retoca esses saberes a seu modo, construindo representações marcadas pelos seus valores, opiniões e crenças. As representações sociais orientam as práticas e comportamentos das pessoas, ou seja, agimos orientados por nossas representações (MOSCOVICI, 1978).

Segundo Sá, representação social é o "saber gerado através da comunicação na vida cotidiana, com a finalidade prática de orientar os comportamentos em situações sociais concretas" (1998, p.68). Uma representação social é sempre de alguém e de alguma coisa. Portanto, ao se falar em representações sociais, deve-se levar em conta, simultaneamente, o sujeito que representa e o objeto representado.

A TRS constitui um corpo abrangente de conhecimentos no qual se identificam três abordagens complementares ${ }^{1}$. A primeira é a abordagem original, liderada por Denise Jodelet, em Paris. Refere-se às representações sociais em sua clássica definição, ou seja, definidas como as modalidades de conhecimento prático, orientadas para a comunicação e a compreensão do contexto social e material em que vivemos. Constituem modos de conhecer que se manifestam como elementos cognitivos, imagens, conceitos, categorias, teorias. Não se reduzem a componentes cognitivos. São fenômenos sociais que, mesmo acessados a partir de seu conteúdo cognitivo, devem ser entendidos a partir de seu contexto de produção (SPINK, 1993). A segunda vertente, a teoria do núcleo central - desenvolvida por J.C. Abric e colaboradores, vincula-se à escola de Aix-en-Provence e define representação social como uma estrutura de dois sistemas: o sistema central, que a norteia e lhe dá estabilidade e o periférico, que flexibiliza sua relação com realidade e a cultura. A terceira vertente, perspectiva societal, foi desenvolvida por Willem Doise, em Genebra, e enfatiza a dimensão sociocognitiva das representações. Conforme Almeida (2009), nessa abordagem, o conteúdo das representações nasce das relações entre o sujeito e os grupos e serve para justificar o encadeamento dessas relações, mantendo, ao mesmo tempo, a especificidade e a identidade de cada grupo. Conforme a autora, mesmo

\footnotetext{
${ }^{1}$ Já podemos mencionar uma quarta vertente, a epistemológica dialógica, com ênfase na linguagem, que tem, como principal protagonista, Yvana Marková.
} 
sem perder de vista sua matriz de origem, a abordagem societal enfatiza as relações entre grupos e sua influência na criação de representações sociais. O presente artigo toma como referência a perspectiva societal de W. Doise (2002) para entender como professores iniciantes de escolas privadas representam a sua profissão.

A proposta de análise das representações sociais na vertente societal considera as representações como princípios geradores de tomadas de posição, ligados às inserções sociais específicas, organizando os processos simbólicos que interferem nas relações sociais. Essa abordagem valoriza os processos intraindividuais, interindividuais, intergrupais e societais e suas interferências na construção das representações. Por meio do intraindividual, os indivíduos organizam suas experiências com o meio ambiente; os processos interindividuais indicam que, nos sistemas de interação, dão-se os princípios explicativos típicos das dinâmicas sociais (seu grupo de pertencimento); processos intergrupais consideram as diferentes posições que os indivíduos ocupam nas relações sociais e os processos societais dizem respeito às produções culturais e ideológicas de uma sociedade ou grupo que criam ou dão suporte às diferenças sociais (ALMEIDA, 2009).

Na abordagem societal, a análise de representações sociais enfatiza três aspectos: o que é compartilhado no grupo, isto é, o consenso grupal; as variações do grupo e as ancoragens das representações. No campo educacional brasileiro, essa abordagem tem sido pouco explorada. Para esta investigação, que recai sobre um grupo específico de professores, a abordagem tornou-se pertinente.

Admitimos que a profissão docente não é nova e reconhecemos que as concepções e os conceitos de profissão docente são históricos e situados. Todas as profissões construíram, ao longo de um tempo, o reconhecimento, um estatuto de profissionalidade plena, através do qual os profissionais se reconhecem, afirmam-se e são distinguidos pela posse de um saber próprio. A docência existiu em muitos formatos e com diversos estatutos ao longo da história, mas a emergência de um grupo profissional estruturado em torno da docência surge na modernidade, precisamente, a partir do século XVIII (ROLDÃO, 2007).

Nóvoa (1991) organizou um modelo para facilitar a análise da história recente dos professores, em que destaca alguns processos que contribuíram para a profissionalização do professorado, tais como a institucionalização da escola como organização pública; a organização do currículo que legitima seu papel social, a exigência de conhecimento profissional específico e o reconhecimento de uma formação própria para o desempenho da função. Esses processos de afirmação profissional são marcados por lutas, conflitos, hesitações e recuos. 
Referindo-se ao contexto português, ao conceito de profissionalização docente, Nóvoa (1995) vincula o modelo de professor ao religioso, à vocação. No entanto, a estatização modificou esse cenário rumo à profissionalização, promovendo o rompimento dessa relação vocacional.

Lüdke e Boing (2004) consideram que, para se constituir como uma profissão, alguns elementos são requeridos e, baseados em Cogan e Barber, elencam quatro critérios comuns a todas as profissões:

a) uma profunda base de conhecimentos gerais e sistematizados; b) o interesse geral acima dos próprios interesses; c) um código de ética controlando a profissão pelos próprios pares; e d) honorários como contraprestação de um serviço e não à manifestação de um interesse pecuniário (LÜDKE; BOING, 2004, p. 1161-1162).

No momento atual, ser professor vai além de transmitir conteúdo tornando-se uma atividade. Conforme pontuam Lüdke e Boing, o professor é:

[...] um intelectual mandatário de quatro dimensões que o diferenciam de outros intelectuais: é mediador, herdeiro, crítico e intérprete da cultura. A escola, segundo os autores, ainda é a instituição privilegiada para a transmissão da cultura na sociedade atual (LÜDKE; BOING, 2004, p.1176).

A despeito das controvérsias em torno da docência como profissão, Cericato (2016) revisando a literatura sobre o assunto - afirma que a docência pode ser reconhecida como uma profissão porque o professor, para ensinar alguém, deve dominar um conhecimento e saber como fazer para ensinar. Trata-se de um trabalho específico, ou seja, refere-se à sistematização de saberes eruditos e não de cunho popular. É um trabalho realizado com objetivo e intencionalidade, mediante apropriação de um conhecimento específico em instituição própria. Uma tarefa que requer domínio nos campos didático e técnico, além de constante reflexão sobre esse fazer. A mesma autora não nega os desafios que ameaçam e põem em risco a docência como profissão. Como principais desafios, destaca: desvalorização e retração salarial, precarização da formação dos professores, ausência de uma carreira docente e evasão profissional (CERICATO, 2016).

A profissão docente tem sido marcada por um processo de proletarização e é nesse contexto e com essa compreensão que investigamos as representações sociais do ser professor entre docentes de escolas privadas em início de carreira.

Como pontua Huberman (1995), três fases são vivenciadas pelos professores durante o ciclo profissional: a entrada na carreira, correspondente aos três primeiros anos de ensino, marcada pelos aspectos de sobrevivência e descoberta; a fase de estabilização na qual o 
professor possui mais confiança no seu trabalho, sente-se mais confortável para alcançar os objetivos didáticos e a, terceira fase, marcada pela diversificação, em que são vivenciados vários sentimentos tais como o questionamento, o desinvestimento e o conservantismo. Huberman (1995) afirma que esse ciclo é um processo, podendo não ser vivenciado na mesma ordem e da mesma forma por todos os professores. Como já foi anunciado, neste artigo, abordamos sujeitos na fase inicial na carreira, com até cinco $\operatorname{anos}^{2}$ de exercício profissional. A entrada na carreira é marcada pelo "choque do real" momento em que o professor entra em contato direto com a complexidade da profissão e faz descobertas. Relaciona-se com o entusiasmo inicial e o sentimento de satisfação em ter sua própria sala de aula para gerir, seus alunos, estar em situação de responsabilidade profissional (HUBERMAN, 1995).

Em estudo sobre a fase inicial da docência, Lima (2006) aponta algumas dificuldades dessa fase tais como: a imitação acrítica de condutas de outros professores; o isolamento; obstáculos na relação com os alunos, suas famílias e na construção de regras de convivência; dificuldade na transferência dos conhecimentos adquiridos na formação inicial para a prática docente. Por ser uma fase tão decisiva da vida profissional, que gera crise e provoca indagações, é um momento propício para a construção de representações sociais. Assim, este artigo enfoca o ser professor nas representações sociais de docentes iniciantes de escolas particulares.

\section{METODOLOGIA}

Trata-se de um trabalho de abordagem qualitativa. Segundo Bogdan e Biklen, essa abordagem "envolve a obtenção de dados descritivos, obtidos no contato direto do pesquisador com a situação estudada, enfatiza mais o processo do que o produto e se preocupa em retratar a perspectiva dos participantes" (BOGDAN; BIKLEN, 1994 p. 13).

Participaram da pesquisa 20 professoras de instituições privadas situadas em Recife-PE. Para a escolha dessas docentes, adotamos os critérios: estar com até cinco anos de exercício na docência e atuar em turmas de Educação Infantil e anos iniciais do Ensino Fundamental de instituições privadas.

Aplicamos um questionário com questões fechadas e abertas. As respostas favoreceram a construção do perfil do grupo pesquisado, além de oferecerem informações sobre o que pensam os sujeitos sobre a profissão docente; desafios e dificuldades enfrentadas em suas práticas; importância da formação para a fase inicial da carreira e expectativas profissionais.

\footnotetext{
${ }^{2}$ Devido a dificuldades para localizar profissionais com exatamente até três anos na carreira, apoiamo-nos em Garcia (1999) e Nono (2011) que consideram professores iniciantes profissionais com até cinco anos em exercício na docência.
} 
Para localizar os participantes, utilizamos da estratégia “ construção de sujeitos em rede”, ou seja, ao chegarmos a uma professora que atendia aos critérios estabelecidos, ela nos indicava outra com perfil idêntico, assim formamos o grupo participante. Este tipo de amostra é denominado por Flick (2009) de "amostra em bola de neve".

Todas as participantes são mulheres com, em média, 32 anos de idade. A formação acadêmica é variada, contamos com professoras em processo de finalização da graduação, graduadas, mestras e uma doutoranda. Das participantes, oito docentes atuavam na Educação Infantil e 12, nos anos iniciais do Ensino Fundamental. Sobre o tempo de exercício docente, sete professoras tinham até um ano de profissão; seis estavam com dois anos, uma afirmou estar há três anos na docência; duas, há quatro anos e quatro responderam que estavam com cinco anos de experiência docente.

Após se traçar o perfil do grupo participante, foi realizada uma análise de conteúdo das respostas às questões abertas do questionário de modo que, atendendo ao referencial de Doise (2002), os resultados pudessem indicar os elementos comuns e as variações das representações sociais do objeto pesquisado.

\section{RESULTADOS E DISCUSSÃO}

Entre os elementos consensuais encontrados nas respostas das participantes, destacamos: a chegada e o acolhimento das docentes nas instituições escolares; o processo de adaptação à escola; a utilidade prática da formação pedagógica para o trabalho do professor iniciante.

A maioria das professoras considera que foi bem recebida e acolhida ao chegar às escolas. Elas informam que receberam apoio da gestão, da coordenação e que foi boa a receptividade por parte dos colegas, como podemos identificar na resposta de $\mathrm{P}-1^{3}$ :

Ao chegar na escola, fui bem recebida e acolhida pelos coordenadores. Eles foram gentis conversando com clareza. Não tive problemas aqui na escola (P-1).

As docentes ressaltam que algo que facilita a iniciação à docência é serem orientadas sobre o dia a dia escolar, filosofia e modo de trabalho da escola. Suas respostas estão em consonância com o que afirmam Gabardo e Hobold (2011). Segundo estas autoras, o apoio recebido facilita as relações que irão vivenciar e ajuda na inserção dessas profissionais no

\footnotetext{
2 Para preservar a identidade das professoras, utilizamos a seguinte codificação: letra P maiúscula significando professora seguida do número de ordem aplicação do questionário. Ex. P-7
} 
contexto escolar. O acompanhamento pedagógico e a boa recepção nas escolas fazem com que professores, em início de carreira, sintam-se mais seguros e menos solitários.

Sobre a adaptação à escola e as experiências marcantes no início da docência, as respostas foram diversas, porém algumas professoras fizeram mais referências às dificuldades. Do grupo, 17 professoras destacaram como dificuldades marcantes no início da profissão: os métodos e filosofia adotados pelas escolas, formas de planejamento, exigências e cobranças. Algumas delas fizeram referência à relação com os alunos, dificuldade para estabelecer uma rotina e lidar com a diversidade em sala de aula. Foram mais incisivas ao se referirem às cobranças e exigências pelo "bom" desempenho por parte da direção das escolas. Afirmam em suas respostas:

[...] Poderia ser melhor... Não temos muito apoio é muito mais cobrança. $(\mathrm{P}-3)$

[...] muitas vezes, a insegurança e o medo travam o professor que está começando, por isso é tão importante a escola mostrar-se solícita e a disposição para auxiliá-lo e não ficar só a exigir da gente (P-8).

Constituiu consenso, nas respostas, a ausência de parceria com as famílias e a falta de educação doméstica dos alunos. Segundo as professoras, estes são grandes obstáculos ao desenvolvimento do trabalho do docente em início de carreira, como vemos na resposta de P-2:

[...] esse desafio requer muita determinação do professor junto ao aluno. No começo, a gente estranha demais, mas vai aprendendo a lidar... (P-2)

Em relação às famílias, foi destacada pelas professoras, a cobrança em torno de resultados. Segundo comentam, os pais reclamam e exigem devido ao elevado investimento na educação dos filhos e às expectativas que depositam na escola. Essa cobrança dos pais repercute nos professores, que sofrem pressão de toda ordem. Afirma uma das respondentes:

Os pais, eles... estão pagando escolas caras e não querem reclamação. Eles querem retorno e cobram da escola, que acaba sugando os professores (P-6).

Ao serem perguntadas sobre a formação no curso de graduação e sua contribuição para o exercício inicial da docência, 19 professoras responderam positivamente. Por exemplo, P-1 afirmou:

[...] o suporte teórico é de extrema importância para o embasamento profissional. 
Responderam ainda que a troca de experiências e os debates em sala de aula durante o curso de formação são importantes e contribuem para se compreender as diferentes perspectivas da docência. Destacam, da formação, os conteúdos de metodologias e práticas de ensino.

[...] As metodologias e as disciplinas de Pesquisa e Prática Pedagógica ${ }^{4}$ dão a oportunidade de vivenciar a teoria e a prática. Me ajudaram bastante (P-7)

Três professoras (P-2, P-15 e P-17) ressaltaram a relevância da teoria, mas concluem dizendo que "a prática sempre será desafiadora" (P-2). Apenas uma fez referência às lacunas que possuem em diversas áreas, as quais ela busca suprir estudando. Corroborando o já constatado por Machado e Medeiros (2015), as professoras admitem que o curso de formação é reconhecido como útil para a prática do professor iniciante.

Quando perguntadas a respeito do apoio da coordenação da escola e dos demais docentes ao professor em início de carreira, as respostas das participantes foram unânimes em relação ao valor desse apoio. Do grupo participante, 18 professoras responderam que os colegas oferecem uma colaboração fundamental. Segundo elas, o apoio por parte desses profissionais facilita o trabalho do docente. É importante para compreender a dinâmica do trabalho na instituição e auxilia o professor iniciante no modo como proceder frente a diferentes situações com as quais se depara e não está acostumado. Conforme afirmaram, a troca favorece o desenvolvimento do processo pedagógico e diminui a angústia vivida pelo iniciante. Para P-3, os colegas professores e a direção ajudam no

[...] tratamento com os pais, preparação dos eventos escolares e outras atividades, principalmente, os projetos coletivos da escola.

No entanto, algumas docentes respondem que, apesar do apoio, a direção e os colegas poderiam respeitar mais as opiniões do docente iniciante na carreira a fim de que ele possa construir sua autonomia.

A participante P-6 acrescenta em sua resposta que o apoio dos colegas e da coordenação deve ser dado a todos os professores e

[...] não apenas àqueles em início de carreira como os que estão no meio e fim.

Para a participante, esse suporte deve ocorrer de modo formal em todas as ocasiões e principalmente em reuniões pedagógicas.

\footnotetext{
${ }^{4}$ Diz respeito à prática pedagógica e ao estágio supervisionado vivenciados no curso de Pedagogia da Universidade Federal de Pernambuco (UFPE).
} 
O apoio de que falam as professoras é tratado por Nono (2011) quando ela aborda a necessidade de os professores fazerem parte de uma comunidade de aprendizagem. A referida autora destaca que o trabalho exige cooperação entre pares, assessoria dos gestores e demais profissionais. A equipe gestora da escola deve considerar o papel do professor e as necessidades de mudanças das práticas pedagógicas, bem como oferecer sugestões e comentários que favoreçam a progressão no trabalho do docente iniciante.

Entre os elementos que variaram nas respostas das professoras, destacamos: a chegada à escola e o acolhimento, os desafios da prática e a (des)valorização docente. Tais variações foram identificadas entre os grupos e nos intergrupos.

Duas professoras (P-3 e P-5), que atuam nos anos iniciais do Ensino Fundamental, que possuem graduação e que estão há menos de dois anos na profissão, relataram dificuldades na chegada às escolas; percebemos que as mesmas não se sentiram acolhidas, como ilustra a fala de P-3:

[...] logo que comecei me senti muito nervosa. Sozinha. Completamente só... Mas, aos poucos, fui ficando mais à vontade e tendo apoio pedagógico.

As respostas das professoras estão de acordo com a literatura, pois Huberman (1995) Lima (2006) e Nono (2011) afirmam que a solidão e o isolamento são sensações comuns aos professores iniciantes. Alguns se sentem inseguros em relação ao estar ou não agindo corretamente frente às situações e se queixam de desinformação quanto às normas administrativas e outras orientações escolares. Sendo assim, preferem ficar em silêncio para não demonstrar fragilidade ou se exporem diante dos colegas veteranos.

Dos desafios enfrentados na prática, três professoras (P-4, P-6, P-7) registraram a falta de autonomia. P-7, por exemplo, destaca não poder realizar uma prática diferenciada, ressalta como maior dificuldade não ter liberdade para exercitar as aprendizagens que obteve em seu curso de graduação. Afirma:

[...] tudo é fiscalizado, a gente fica presa às amarras do plano estabelecido... Difícil falar em autonomia ... Nem pensar!... A gente toma um choque, depois vai se adaptando. (P-7)

Duas docentes atuam de Educação Infantil (P-4 e P-6), ambas com até dois anos de carreira, possuem mestrado e trabalham na mesma escola. Mesmo sendo mestras, vivenciam o desafio de não serem autônomas em suas práticas pedagógicas. Lima (2006), em estudo com alfabetizadoras iniciantes, afirma que um dos desafios enfrentados é a falta de autonomia. Por exemplo, ter que seguir cartilhas/textos prontos, planejamentos etc. Esse descontentamento foi manifestado nas respostas dessas duas professoras. 
A indisciplina em sala de aula foi pontuada por quatro professoras (P-1, P-5, P-6 e P13) como algo que prejudica o trabalho docente e choca o professor iniciante na profissão. As participantes indicam em suas respostas episódios de violência entre as crianças e, também, delas para com a professora. Eis um exemplo:

[...] tem de tudo. A gente pensa que não, mas menino chama palavrão, menino agride os colegas na sala, no recreio. Eles gritam com a gente. Tudo tem que ser na hora, parece que tão falando com a empregada... No começo, eu ficava chocada ... Agora, estou acostumando. Porém, não são todos não. (P-13)

A referência à indisciplina dos alunos como obstáculo ao início da docência está em consonância com a literatura. Para vencer esses desafios, o professor cria estratégias e desenvolve habilidades que permitem prosseguir com seu trabalho. Lima (2006) ressalta que o início da docência é marcado por um misto de desconforto e satisfação, que acontece em maior ou menor proporção para cada iniciante.

Ainda como variação nas respostas, a desvalorização foi pontuada nas respostas de cinco docentes. Elas fizeram referências à falta de reconhecimento e desprestígio social do professor, o pode ser visto no registro de P-14 e de P-5, respectivamente:

[...] desvalorizado em vários sentidos, do não reconhecimento do seu trabalho e sua importância...

[...] o valor do professor, em sala, é mínimo.

Os baixos salários foram lembrados nas respostas de três professoras.

Para apreender as representações sociais do ser professor capturadas nas respostas das participantes, destacamos as razões que mobilizaram as docentes para escolherem a profissão, os elementos que lhes dão satisfação, insatisfação e as suas perspectivas para a docência.

Quando questionadas sobre o significado de ser professor na atualidade, 15 professoras responderam que ser professor é ser mediador de conhecimento. Enfatizaram saber respeitar e lidar com a diversidade social e cultural dos alunos, bem como tornar o outro autônomo no processo de pensar. Seis professoras, das 15 acima citadas, complementaram suas respostas dizendo que ser professor é ter comprometimento social e através da Educação, contribuir para transformar a sociedade. Em sua resposta, P-2 sugere que, hoje em dia, o professor exerce outras funções, além das que lhe seriam próprias. Afirma:

[...] pra mim, o significado de "ser professor" hoje é o mesmo significado que tinha anos atrás. Professor é aquele que ensina pedagogicamente, é aquele que leciona. Não é pai ou mãe, não é enfermeira, não é padre ou pastor. (P-2) 
Duas professoras destacaram em suas respostas que ser professor é ser desvalorizado, tanto socialmente quanto em termos salariais. Uma delas (P-17) respondeu que, para ser professor, é necessário amor à profissão. Outra professora (P-7) não se posicionou quanto ao significado de ser professor respondeu apenas:

[...] acredito que estamos em um processo de redefinição, o professor tentando reconstruir sua identidade.

Sobre as razões que levaram a escolher a profissão docente, dez professoras comentaram que tinham afinidade e identificação com a área de Educação e admitem que, na profissão docente, encontrariam "realização pessoal e profissional" (P-8). Dessas docentes, uma disse que esta foi sua segunda opção, outra respondeu ter tido influência familiar e outra respondeu que o mercado de trabalho foi o fator que a influenciou. Três professoras responderam que a escolha sofreu influência familiar, mas não aprofundaram essas respostas e outras três responderam ter escolhido a profissão para contribuir com a formação dos futuros cidadãos e profissionais. Uma participante, P-4, ressalta ter feito a melhor escolha, mesmo esta não tendo sido sua primeira opção. Apenas uma professora (P-5), respondeu não ter sido aprovada no curso que seria sua primeira opção tendo sido remanejada para o curso de Pedagogia. A mesma docente reconheceu que, com o decorrer do curso, passou a gostar e a defender a profissão. P10 não comenta o que a levou a escolher a docência e outra professora respondeu apenas que escolheu Pedagogia devido à possibilidade de atuar em coordenação pedagógica.

Sobre o que mais agrada na profissão, 14 participantes responderam que é perceber a evolução do aluno. Ressaltam a aprendizagem e o desenvolvimento dos alunos como o que há de mais gratificante no trabalho docente. Uma docente, P-6, respondeu:

[...] poder ver a evolução do meu aluno. Perceber algo que ele(a) não conseguia fazer e agora faz.

Duas professoras responderam que ficam satisfeitas quando os pais, ao verem o desenvolvimento de seus filhos, reconhecem o trabalho do professor. Três participantes relatam como o que mais lhes agrada é perceber que, através da Educação, elas podem contribuir na formação de sujeitos mais dignos, como podemos ver em uma fala:

[...] contribuir para estarem no mundo com maior dignidade. [...] O que mais satisfaz é poder aprender todos os dias com meus alunos... Um dia nunca é igual ao outro, a gente está sempre aprendendo com os alunos, a escola e a profissão. (P-8) 
Identificamos nas respostas das professoras a condição de bem-estar na docência, o que estaria em consonância com autores como Rausch e Dubiella (2013) e Esteve (1999). Na visão desses autores essa satisfação/bem-estar influencia diretamente a forma como o professor percebe, desenvolve e reconhece seu trabalho. A literatura aponta, como indícios de satisfação, a relação professor-aluno, professor-professor e aprendizagem dos educandos.

Sobre o que mais incomoda as professoras na profissão, cinco participantes responderam destacando a desvalorização do profissional da área de Educação e a falta de reconhecimento social do professor. De modo semelhante, P-9 ressaltou:

Infelizmente quem trabalha com Educação não é realmente valorizado, pois ao falar que sou professora recebo muitos olhares de reprovação... (P-9)

Para três professoras, o que mais as incomoda é a indisciplina por parte de seus alunos. Elas enfatizaram a falta de respeito com o professor como comportamento que afeta negativamente o trabalho docente. Para P-4,

[...] a grande dificuldade é que encontramos alunos indisciplinados que desrespeitam o professor e atrapalham de alguma forma as aulas chamando a atenção de todos.

Outras três participantes elencaram como elementos prejudiciais ao trabalho docente: relação difícil, cobrança e a falta de colaboração dos pais. Uma delas destacou que eles, muitas vezes, não estão dispostos a participarem da formação de seus filhos. Ressaltaram, como insatisfação, a falta de autonomia no exercício docente. Mencionaram os limites do tempo pedagógico para planejar, o trabalho feito em domicílio e o excesso de atividades extras como a execução de projetos.

Os resultados sugerem que a insatisfação docente está associada a fatores como baixos salários, desvalorização profissional, ausência da família no apoio e acompanhamento dos alunos e indisciplina. Tais fatores estão em sintonia com o que é dito por Rausch e Dubiella (2013).

Ao serem perguntadas sobre suas perspectivas para a docência, seis professoras disseram que esperam, no futuro, atuar no Ensino Superior, estarem concursadas, atuando como docentes de universidades, pois desejam se tornar pesquisadoras da área educacional. Duas professoras responderam que gostariam de continuar atuando na Educação Básica.

Quatro professoras disseram que acreditam que estarão realizadas pela formação que puderam proporcionar aos alunos. Elas possuem expectativas positivas em relação à docência e acreditam que, futuramente, os profissionais de Educação serão mais valorizados. A 
participante $\mathrm{P} 4$, por exemplo, cogita essa valorização por acreditar que a desvalorização tem acarretado a "escassez" de professores. Na mesma direção, duas professoras responderam que estarão cansadas, uma delas relata insatisfação com a questão salarial afirmando:

[...] creio que estarei insatisfeita com a remuneração dada para os professores.

Uma professora (P-5) não apresentou diretamente perspectivas de como, pessoalmente, estaria na profissão; em suas projeções para o futuro respondeu:

\section{[...] penso futuramente abrir uma escola própria.}

Por fim, uma única docente manifestou o desejo de estar atuando em turmas de anos iniciais de instituição pública.

\section{CONSIDERAÇÕES FINAIS}

Detectamos que as professoras em início de carreira de escolas privadas construíram representações do ser professor como mediador do conhecimento. Houve também por parte de um grupo menor das professoras (4) um olhar positivo para a área de Educação, as mesmas acreditam que, no futuro, essa área será mais valorizada. No entanto, nos resultados, prevaleceu, na representação social do ser professor, certo pessimismo com a docência. Não houve um consenso quanto às perspectivas para o futuro, porém a maioria das professoras deseja atuar em outros níveis de ensino, particularmente o superior. Embora duas professoras sinalizem sua insatisfação, não foi cogitada, pelas participantes, a possibilidade de abandonar a docência.

Como aspectos positivos, as docentes apontam a possibilidade de contribuírem para a aprendizagem dos alunos. O fenômeno atinge os diversos contextos, ou seja, apesar de as escolas privadas oferecerem melhores condições de trabalho, as docentes não estão livres desse impacto inicial. Detectamos o choque de realidade quando relatam a relação com os alunos, articulação teoria/prática e sofrem cobrança por parte da gestão e das famílias dos alunos.

Apoiadas na abordagem societal de W. Doise, identificamos que o grupo pesquisado partilha uma representação social do ser professor pautada na possibilidade de formação e mediação. Essas representações sociais são marcadas pelos sentimentos de desvalorização e falta de reconhecimento social da docência. Apesar desses sentimentos, a maioria das participantes deseja continuar exercendo a função de professora.

A pesquisa contribui para fortalecer a literatura quando afirma que a fase inicial do ciclo de desenvolvimento profissional docente impacta, choca o professor. Com base nos resultados, 
indicamos a necessidade de se pensar alternativas que melhor acolham e subsidiem o trabalho do docente em início de carreira.

\section{REFERÊNCIAS}

ALMEIDA, Angela Maria. de Oliveira. Abordagem societal das representações sociais. Sociedade e Estado, vol.24, n.3, p.713-737, 2009,Disponível em: $<$ http://www.scielo.br/scielo.php?pid=S0102-69922009000300005\& script=sci_abstract\&tlng=pt $>$. Acesso em: set.2018.

BOGDAN, Robert; BIKLEN, Sari. Fundamentos da investigação qualitativa em educação: uma introdução. In: Investigação qualitativa em Educação: uma introdução à teoria e aos métodos. Porto Editora: Porto. 1994.

CERICATO, Itale Luciane. A profissão docente em análise no Brasil: uma revisão bibliográfica. Rev. Brasileira de Estudos Pedagógicos. Brasília, v.97, n. 246, p. 273-289, maio/ago. 2016.

CORRÊA, Priscila Monteiro; PORTELLA, Vanessa Cristina Maximo. As pesquisas sobre professores iniciantes no Brasil: uma revisão. Olhar de professor, Ponta Grossa, vol. 15, n. 2, p. 223-236, 2012.

CUNHA, Renata Cristina da; VOLTARELLI, Monique Aparecida; COSTA, Cátia Silvana da. Pesquisas sobre o professor iniciante no programa de pós-graduação em educação da UFSCAR: o estado do conhecimento de 2000 -2010. Revista Educação e Linguagens, Campo Mourão, v. 2, n. 3, jul/dez. 2013.

DOISE, Willem. Da psicologia social à psicologia societal. Psicologia: Teoria e Pesquisa, v.18, n.1, p. 27-35, 2002.

ESTEVE, José Manuel. O mal-estar docente: a sala de aula e a saúde dos professores. Bauru: EDUSC, 1999.

FLICK, Uwe. Observação e Etnografia. In: Introdução à pesquisa qualitativa. $3^{\mathrm{a}}$ ed., Porto Alegre: Artmed, 2009, p. 203-218.

GABARDO, Cláudia Valéria.; HOBOLD, Márcia de Souza. Início da docência: investigando professores do ensino fundamental. Revista Formação Docente. Belo Horizonte, v. 03, n. 05, ago/dez. 2011.

GARCÍA, Marcelo Carlos. Formação de professores para uma mudança educativa. Porto: Porto Ed., 1999.

UBERMAN, Michäel. O ciclo de vida profissional dos professores. In: NÓVOA, A. António (Org.). Vida de professores. 2. ed. Porto: Porto Ed., 1995. p. 31-61.

LIMA, Emília Freitas de. (Org.). Sobrevivências no início da docência. Brasília: Liber Livros, 2006. 
LÜDKE, Menga.; BOING, Luiz Alberto. Globalização e educação: precarização do trabalho docente II - caminhos da profissão e da profissionalidade docentes. Educação e Sociedade, Campinas, v.25, n.89, set/dez. 2004.

MACHADO, Joceane da Silva. Trilhando pesquisas sobre professores iniciantes: um estudo do estado da arte. Revista Humanidades e Inovação, UFSM, v.4, n. 2, 2017.

MACHADO, Laeda Bezerra.; MACHADO, Renata Medeiros. Implicações do curso de Pedagogia para a prática de professores iniciantes. Revista Profissão Docente, Uberaba, v. 15, no 32, p. 29-45, fev./jul. 2015.

MOSCOVICI, Serge. A representação social da psicanálise. Tradução de Álvaro Cabral. Rio de Janeiro: Zahar, 1978.

Representações sociais: investigações em psicologia social. Petrópolis: Vozes, 2003.

NONO, Maévi Anabel. Professores iniciantes: o papel da escola em sua formação. Porto Alegre: Ed. Mediação, 2011.

NÓVOA, Antônio. Para o estudo sócio-histórico da gênese e desenvolvimento da profissão docente. Teoria \& Educação. Porto Alegre, n. 4, p. 109-139, 1991.

PAPI, Silmara de Oliveira Gomes; MARTINS, Pura Lúcia Oliver. Professores iniciantes: as pesquisas e suas bases teórico-metodológicas. Linhas Críticas, Brasília, v. 14, n. 27, p.251269, jul./dez. 2009.

PAPI. Silmara de Oliveira Gomes; CARVALHO, Camila Boczkoski. Professores iniciantes: um panorama das investigações brasileiras. Olhar de professor, Ponta Grossa, vo. 16, n. 1, p. 185-202, 2013.

RAUSCH, Rita Buzzi; DUBIELLA, Eliani. Fatores que promoveram mal ou bem-estar ao longo da profissão docente na opinião de professores em fase final de carreira. Rev. Diálogo Educacional, Curitiba, v. 13, n. 40, p. 1041-1061, set./dez. 2013.

ROLDÃO, Maria do Céu. Função docente: natureza e construção do conhecimento profissional. Revista Brasileira de Educação, Rio de Janeiro, v.12, n.34, jan/abr. 2007.

SÁ, Celso Pereira. A construção do objeto de pesquisa em representações sociais. Rio de Janeiro: EdUERJ, 1998.

SPINK, Mary Jane. O conceito de representação social na abordagem psicossocial. Cad. Saúde Pública. Rio de Janeiro, vol. 9, n. 3, p. 300-308, jul./set. 1993.

\section{SOBRE OS AUTORES}

Laeda Bezerra Machado é Doutora em Educação. Professora Adjunta do Departamento de Administração Escolar e Planejamento Educacional, atuante no Programa de Pós-Graduação em Educação - Núcleo de Formação de Professores e Prática Pedagógica da Universidade Federal de Pernambuco (UFPE).

E-mail: laeda01@gmail.com 
Camila Afonso Ferreira de Araújo é estudante concluinte do Curso de Pedagogia da Universidade Federal de Pernambuco (UFPE) e bolsista FACEPE.

E-mail: camila.afonsoferreira@gmail.com

Lucivânia Barbosa Evangelista é estudante do Curso de Pedagogia da Universidade Federal de Pernambuco (UFPE) e bolsista PIBIC-CNPq

E-mail: luci_vania@yahoo.com.br 